\title{
Estimation of Complement Components (C3 and C4) and hs-CRP Level in Kidney Failure Patients
}

\author{
Zaid N. Elia ${ }^{1 *}$, Nisreen W. Mustafa ${ }^{2}$ \\ ${ }^{1}$ Department of Medical Laboratory Technique, Erbil Technical Health College, Erbil Polytechnic University, Erbil, Kurdistan Region, Iraq, \\ ${ }^{2}$ Electron Microscope Unit, College of Pharmacy, University of Basrah, Iraq
}

\author{
*Corresponding author: \\ Zaid N. Elia, \\ Department of Medical \\ Laboratory Technique, Erbil \\ Technical Health College, \\ Erbil Polytechnic University, \\ Erbil, Kurdistan Region, Iraq. \\ Mobile: 07507668497. \\ E-mail: zaidbio82@yahoo. \\ com

\begin{tabular}{l} 
Received: 07 August 2019 \\
Accepted: 21 November 2019 \\
Published: 01 December \\
2019 \\
\hline DOI \\
10.25156/ptj.v9n2y2019.pp70-75
\end{tabular} \\ Received: 07 August 2019 \\ Accepted: 21 November 2019 \\ 10.25156/ptj.v9n2y2019.pp70-75
}

\section{A B S TR A C T}

Several kidney diseases associated with complement activation. Complement activation occurs in progressive chronic kidney disease and may contribute to the chronic inflammation that is characteristically found in the kidney. This study was aimed to detect the level of complement system in kidney failure patients. This study was included (30) patients with renal failure and (15) healthy donors as control group. Serum samples separated from the whole blood of patients and healthy individuals. C3, C4, and high sensitive C- reactive protein (hsCRP) levels were estimated for all samples. The results were analyzed according to patients who were dialysis, non-dialysis, with diabetes, without diabetes, with high blood pressure, and without high blood pressure. The results showed that there was a significant increase $(P<0.05)$ in C3 level for patients with renal failure $(154.12 \mathrm{mg} / \mathrm{dl})$ compared to control group $(126.08 \mathrm{mg} / \mathrm{dl})$ while C4 level for renal failure patients $(35.38 \mathrm{mg} / \mathrm{dl})$ showed no significant change compared to control group $(36.26 \mathrm{mg} / \mathrm{dl})$. However, C3 level of patients under dialysis $(152.15 \mathrm{mg} / \mathrm{dl})$, not dialysis $(162.01 \mathrm{mg} / \mathrm{dl})$, with diabetic $(155.80 \mathrm{mg} / \mathrm{dl})$, and without diabetic $(153$ $\mathrm{mg} / \mathrm{dl}$ ) recorded significant elevation compared with control group ( $126.08 \mathrm{mg} / \mathrm{dl})$ but C4 level did not show any significant change for all groups. $\mathrm{C} 3$ and $\mathrm{C} 4$ concentrations did not record significant alteration $(P<0.05)$ in patient with hypertension, nonhypertension, and control group. Moreover, seropositivity of CRP for patients with renal failure was ranged from $33.33 \%$ to $60 \%$ in all patients groups included in this study. hsCRP concentration significantly elevated $(P<0.05)$ in under dialysis $(1.787 \mathrm{mg} / \mathrm{L})$, nondialysis $(1.583 \mathrm{mg} / \mathrm{L})$, with diabetic $(2.766 \mathrm{mg} / \mathrm{L})$, nondiabetic $(1.066 \mathrm{mg} / \mathrm{L})$, with hypertension $(1.84 \mathrm{mg} / \mathrm{L})$, and nonhypertension $(1.26 \mathrm{mg} / \mathrm{L})$ when compared with control group ( $0.667 \mathrm{mg} / \mathrm{L})$. The present findings suggest that the increased serum levels of C3, C4, and hs-CRP reflect the of kidney injury. Hence, this reflects the complement system as an important mediator of kidney injury and the role of anti-complement therapy in nephropathy will expand in the future.

Keywords: Complement; Inflammatory marker and diabetic; Kidney failure

\section{INTRODUCTION}

Kidney disease is a heterogeneous group of disorders that affecting the structure and function of kidney. Even mild abnormalities in kidney are associated with developing complications in other organs as well as mortality. Duration of 3 months or fewer is defined as acute while duration of greater than 3 months is termed chronic (Bedford et al., 2012). Renal failure is the result of loss of homeostatic regulation which is ensured by the kidneys. The nephrons are injured by immunological or toxic injury that may injure the tubule, the glomerulus, or both together. Thus, a significant reduction in functioning renal mass must have occurred much earlier than the onset of significant symptoms or any biochemical alterations in blood (Eknoyan et al., 2004).

Renal failure is two types acute and chronic renal failure. Chronic renal disease (also known as chronic kidney disease [CKD] is progressive kidney function loss over a period of months or years included five stages. Each stage is a progression through low and deteriorating glomerular filtration rate (GFR), which is usually measured by levels of creatinine in the blood (Johnson et al., 2004).

The mammalian kidney is a structurally complex organ. Nephron is functional unit of the kidney, which plays several important roles in maintaining body homeostasis. The main functions include waste products excretion the of metabolism, water balance and regulation of body salt, extracellular fluid volume maintenance, maintenance of acid-base balance, and foreign substances elimination such as chemicals and drugs (Khan and Khan, 2015). Acute renal failure is defined as a rapid and usually reversible disorder in GFR that may occur either renal function is normal or with renal disease (Lameire et al., 2005).

The complement system was recognized as a heatlabile protein that killing of bacteria, functioning as an 
amplification system of humeral immunity in innate immunity as well as regulate adaptive immunity. Besides playing an important role in body defense against infection, the main functions of the complement system are linking between innate and adaptive immunity and clearing apoptotic cells and immune complexes. The complement system consists of three activation pathways (classical, alternative, and lectin), a terminal lytic pathway, plasma and membrane-associated control proteins, and cell surface receptors for the effectors molecules generated on activation of the system. Activation of the complement proteins occurs in the plasma and extracellular space (Carroll and Isenman, 2012).

Complement system component provide a major line of defense against bacteria, viruses, and fungi. The complement system also facilitates the removing of immune complexes and damaged cells. Inactive complement proteins circulate in plasma and are activated through three pathways: Classical pathway, alternative pathway, and mannose-binding lectin (MBL) pathway. The complement system produces several fragments during that have potent cytolytic or pro-inflammatory effects. Some of these fragments are soluble and can be detected in plasma (e.g., C3a and C5a) and some covalently bind to target cells (e.g., C4d and C3d). This system is activated rapidly on damaged cells and pathogens. Complement system discriminates the different surfaces by the balance between activator and regulatory proteins (Joshua and Thurman, 2015).

The activation trigger is detection of threats such as pathogens, apoptotic cells, and altered self-molecules as a result of injury, virus infection, hypoxia, or malignancy. The molecules which initiate of the complement cascade are: C1q molecule which binds to immunoglobulin complexes or pathogen and activates the classical pathway. Whereas, MBL associated with the recognition of mannans (find on the surface of microorganisms) to initiate the lectin pathway and finally, properdin, which is the alternative pathway regulator. All pathways lead to the formation membrane attack complex (C5b-9) (Kościelska-Kasprzak et al., 2014).

Complement activation causes tissue injury in a wide range of autoimmune and inflammatory diseases. Complement activation can damage host tissues if the response to infection is sufficiently strong or widespread, when activated by autoantibodies and immune complexes, in patients deficient in complement regulatory proteins, and in patients with gain of function mutations. Systemic complement activation, as occurs during sepsis or dialysis with incompatible membranes, causes vascular leak and sequestration of leukocytes in the pulmonary circulation.
At the local level, complement activation within the glomerular capillary walls causes cell activation, glomerular inflammation, and injury (Joshua and Thurman, 2015).

Increasing evidence has been accumulated showing that complement activation is implicated in the pathogenesis of different non-antibody-mediated glomerular diseases and in the general progression of renal disease, regardless of the initial insult (Angeletti et al., 2017). Complement proteins are a major constituent of the urine of proteinuric patients (Proteinuria is a strong predictor of progression in CKD). Complement is activated in the tubular lumen through the alternative pathway, and complement activation products are deposited on the apical surface of tubular epithelial cells. Recent animal studies have suggested that complement activation in the tubular compartment plays an important role in the proteinuria-associated tubulointerstitial injury. Complement deficiency, depletion or inhibition all reduce the tubular cell damage and interstitial fibrosis that develops in proteinuric animals (Tang and Sheerin, 2009). Different inflammatory stimulation upregulate complement production in kidney tissue (Cravedi and Heeger, 2014).

The renewed appreciation of the complement system role as a mediator and marker of renal damage has led to numerous recent investigations in the field of complement and renal disease. The present study was aimed to determine the role of the complement system in kidney failure by assessment complement components (C3 and C4) and measure the inflammatory marker high sensitive C- reactive protein (hsCRP) in kidney failure patients under dialysis, nondialysis, with diabetic, nondiabetic, with hypertension. and nonhypertension.

\section{MATERIALS AND METHODS}

A total of 30 blood samples were collected from patients with kidney failure confirmed clinically and by measuring creatinine and urea in the blood. The studied patients were all adults (18-88 years old age). Patients samples were grouped as patients under dialysis, non-dialysis patients, patients with diabetic, non-diabetic patients, patients with high blood pressure, and non-high blood pressure patients.

The patients were complaining from reduced amount of urine, swelling of legs, ankles, and feet and fatigue. The control group included 15 healthy donors. Sera were separated and kept at $-20^{\circ} \mathrm{C}$ until used.

Blood samples were collected and processed, and then sera were subjected to the following tests:

- C3 test and C4 test

- hsCRP test. 


\section{Statistical Analysis}

One-way ANOVA and independent $t$-test was used to compare the differences between $\mathrm{C} 3$ and $\mathrm{C} 4$ concentrations means for patients and healthy donors sera using the SPSS program. Results were considered significant at $P<0.05$.

\section{RESULTS}

Figure 1 shows that $53 \%(n=16)$ of patients were male and $47 \%(n=14)$ of patients were female.

Figure 2 shows that there were $80 \%(n=24)$ of kidney failure patients under dialysis and 20\% $(n=6)$ of patients nondialysis.

Figure 3 denote that there were $60 \%(n=18)$ of kidney failure patients have diabetes and $40 \%(n=12)$ of patients do not have diabetes.

The percentage of kidney failure patients suffering from hypertension was $83.3 \%(n=25)$ and $16.7 \%(n=5)$ of patients was nonhypertension, [Figure 4].

The level of C3 was measured in all study groups sera using a single radial immune diffusion plate. Statistical analysis for the results showed significant difference $(P<0.05)$ between C3 concentrations mean of patient with kidney failure $(154.12 \mathrm{mg} / \mathrm{dl})$ and C3 concentrations mean of control group $(126.08 \mathrm{mg} / \mathrm{dl})$, while $\mathrm{C} 4$ mean $(35.38 \mathrm{mg} / \mathrm{dl})$ revealed non-significant $(P<0.05)$ alteration comparing with control group $(36.26 \mathrm{mg} / \mathrm{dl})$, [Table 1].

The concentration of hsCRP significantly elevated $(P<0.05)$ in patients $(1.746 \mathrm{mg} / \mathrm{L})$ comparing with the control group $(0.667 \mathrm{mg} / \mathrm{L})$ and $50 \%$ of kidney failure patients recorded positive results for qualitative CRP test, [Table 1].

One-way ANOVA test was used to comparing the data of renal failure patients under dialysis, non-dialysis patients, and control groups. The result of the present study revealed a statistically significant difference $(P<0.05)$ between the groups. C3 concentrations mean for patients under dialysis $(152.15 \mathrm{mg} / \mathrm{dl})$ and non-dialysis patients $(162.01 \mathrm{mg} / \mathrm{dl})$ statistically elevated comparing with the control group $(126.08 \mathrm{mg} / \mathrm{dl})$ but were not differences between each

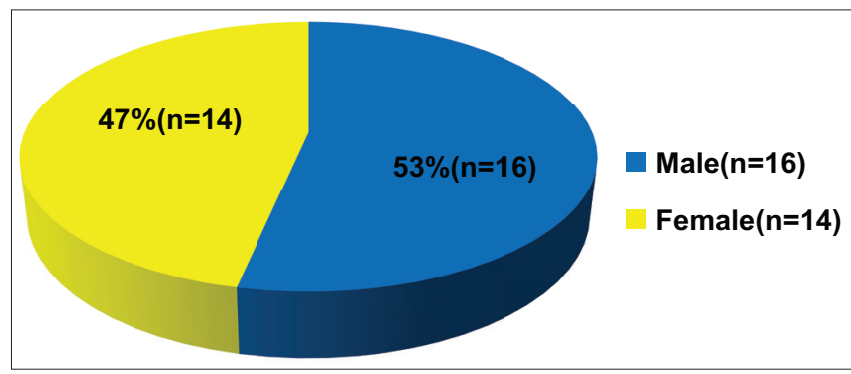

Figure 1: Numbers and percentages of male and female patients kidney failure

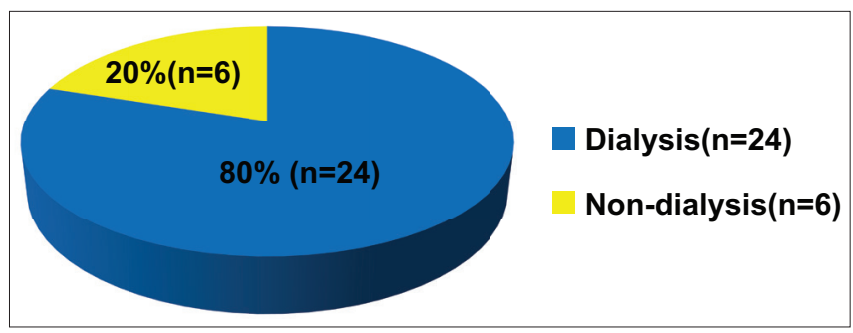

Figure 2: Numbers and percentages of kidney failure patients under dialysis and nondialysis

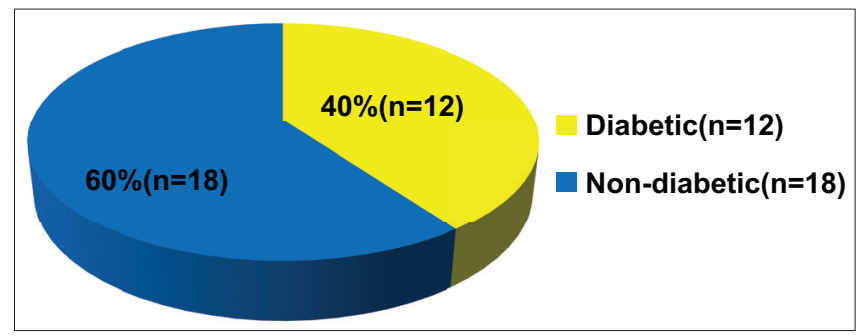

Figure 3: Numbers and percentages of kidney failure patients with diabetes and without diabetes

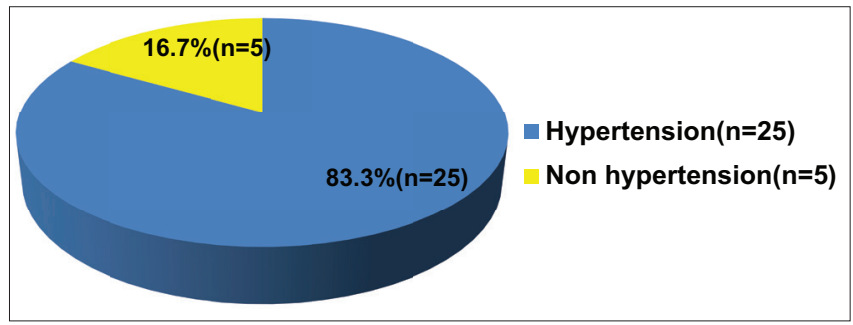

Figure 4: Numbers and percentages of kidney failure patients with hypertension and without hypertension

Table 1: The mean concentration of serum complement components (C3, C4 mg/dl) and hsCRP ( $\mathrm{mg} / \mathrm{L})$ in $\mathrm{KF}$ patients and control group

\begin{tabular}{|c|c|c|c|c|c|c|c|}
\hline \multirow[t]{3}{*}{ Groups } & \multicolumn{2}{|c|}{ C3 } & \multicolumn{2}{|c|}{$\mathrm{C} 4$} & \multicolumn{3}{|c|}{ hsCRP } \\
\hline & Mean $(\mathrm{mg} / \mathrm{dl}) \pm \mathrm{SD}$ & Range (mg/dl) & Mean $(\mathrm{mg} / \mathrm{dl}) \pm \mathrm{SD}$ & Range (mg/dl) & Mean $(\mathrm{mg} / \mathrm{L}) \pm \mathrm{SD}$ & +ve & -ve \\
\hline & & & & & & $\%$ & $\%$ \\
\hline $\mathrm{KF}(n=30)$ & $154.12 \pm 35.56$ & $90.3-200$ & $35.38 \pm 13.60$ & $19.3-60.2$ & $1.746 \pm 0.958$ & 50 & 50 \\
\hline$C(n=15)$ & $126.08 \pm 20.54$ & $88-155$ & $36.26 \pm 10.09$ & $19.5-50.7$ & $0.667 \pm 0.160$ & 0 & 100 \\
\hline$P$-value & \multicolumn{2}{|c|}{0.007} & \multicolumn{2}{|c|}{0.827} & \multicolumn{3}{|c|}{0} \\
\hline
\end{tabular}

KF: Kidney failure, hsCRP: High sensitive C- reactive protein 
other. Meanwhile, C4 result did not show any difference $(P<0.05)$ among the same groups, [Table 2].

Significant elevations $(P<0.05)$ were recorded for hsCRP of patients under dialysis $(1.787 \mathrm{mg} / \mathrm{L})$ and non-dialysis patients $(1.583 \mathrm{mg} / \mathrm{L})$ when compared with control $(0.667 \mathrm{mg} / \mathrm{L})$ whereas no significate alteration appeared between dialysis and non-dialysis groups. Furthermore, CRP test revealed $54.16 \%$ and $33.33 \%$ positive results of renal failure patients under dialysis and non-dialysis patients, respectively, [Table 2].

Statistical elevated $(P<0.05)$ of $\mathrm{C} 3$ concentrations mean in renal failure patients with diabetic $(155.80 \mathrm{mg} / \mathrm{dl})$ and non-diabetic patients $(153.0 \mathrm{mg} / \mathrm{dl})$ when compared with control group $(126.08 \mathrm{mg} / \mathrm{dl})$ but $\mathrm{C} 4$ results revealed no significant difference $(P>0.05)$ among groups, [Table 3].

The concentrations of hsCRP of diabetic $(2.766 \mathrm{mg} / \mathrm{L})$ and non-diabetic $(1.066 \mathrm{mg} / \mathrm{L})$ groups significantly elevated $(P<0.05)$ between each other and when compared to each group with control $(0.667 \mathrm{mg} / \mathrm{L})$. The positive result of renal failure patients with diabetic and non-diabetic patients for CRP test was (58.33\% and 44.44, respectively), [Table 3].
When categorized patients included in this study according to high blood pressure, statistical analysis of result revealed that the mean concentration of $\mathrm{C} 3 \mathrm{did}$ not record significant alteration $(P>0.05)$ in hypertension (154.45 mg/dl), nonhypertension (152.5 mg/dl), and control (144.77 mg/dl), [Table 4].

Significant elevations $(P<0.05)$ were recorded for hsCRP of patients with hypertension $(1.84 \mathrm{mg} / \mathrm{L})$ and non-hypertention patients $(1.26 \mathrm{mg} / \mathrm{L})$ when compared with control $(0.667 \mathrm{mg} / \mathrm{L})$. Positive result of renal failure patients with hypertension and non-hypertension patients for CRP test was $48 \%$ and $60 \%$, respectively, [Table 4].

\section{DISCUSSION}

The wide variety of kidney diseases associated with complement activation indicates there is a linkage about the structure or function of the kidney that makes it particularly sensitive to complement-mediated injury. (Joshua and Thurman, 2015). Excessive complement system activation leads to pathological effects (Pechman et al. 2008).

Table 2: The mean concentration of serum complement components (C3, C4 mg/dl) and hsCRP (mg/L) in renal failure patients under D, ND patients, and control group (C)

\begin{tabular}{|c|c|c|c|c|c|c|c|}
\hline \multirow[t]{3}{*}{ Groups } & \multicolumn{2}{|c|}{ C3 } & \multicolumn{2}{|c|}{$\mathrm{C} 4$} & \multicolumn{3}{|c|}{ hsCRP } \\
\hline & \multirow[t]{2}{*}{ Mean $(\mathrm{mg} / \mathrm{dl}) \pm \mathrm{SD}$} & \multirow[t]{2}{*}{ Range (mg/dl) } & \multirow[t]{2}{*}{ Mean $(\mathrm{mg} / \mathrm{dl}) \pm \mathrm{SD}$} & \multirow[t]{2}{*}{ Range (mg/dl) } & \multirow[t]{2}{*}{ Mean $(\mathrm{mg} / \mathrm{L}) \pm \mathrm{SD}$} & $+\mathrm{ve}$ & -ve \\
\hline & & & & & & $\%$ & $\%$ \\
\hline $\mathrm{D}(n=24)$ & $152.15 \pm 34.83$ & $90.3-188$ & $34.56 \pm 14.24$ & $19.3-60.2$ & $1.787 \pm 0.878$ & 54.16 & 45.84 \\
\hline $\mathrm{ND}(n=6)$ & $162.01 \pm 40.72$ & $87-200$ & $38.66 \pm 11.16$ & $20-55$ & $1.583 \pm 1.316$ & 33.33 & 66.67 \\
\hline$C(n=15)$ & $126.08 \pm 20.54$ & $88-155$ & $36.26 \pm 10.09$ & $19.5-50.7$ & $0.667 \pm 0.160$ & 0 & 100 \\
\hline$P$-value & \multicolumn{2}{|c|}{0.023} & \multicolumn{2}{|c|}{0.76} & \multicolumn{3}{|c|}{0} \\
\hline
\end{tabular}

D: Dialysis, ND: Non-dialysis, hsCRP: High sensitive C- reactive protein

Table 3: Mean concentration of serum complement components (C3, C4 mg/dl) and hsCRP (mg/L) in renal failure patients with DI, NDI patients, and control group (C)

\begin{tabular}{|c|c|c|c|c|c|c|c|}
\hline \multirow[t]{3}{*}{ Groups } & \multicolumn{2}{|c|}{ C3 } & \multicolumn{2}{|c|}{ C4 } & \multicolumn{3}{|c|}{ hsCRP } \\
\hline & \multirow{2}{*}{ Mean $(\mathrm{mg} / \mathrm{dl}) \pm \mathrm{SD}$} & \multirow[t]{2}{*}{ Range (mg/dl) } & \multirow{2}{*}{ Mean $(\mathrm{mg} / \mathrm{dl}) \pm \mathrm{SD}$} & \multirow[t]{2}{*}{ Range (mg/dl) } & \multirow[t]{2}{*}{ Mean $(\mathrm{mg} / \mathrm{L}) \pm \mathrm{SD}$} & \multirow{2}{*}{$\begin{array}{c}\text { +ve } \\
\%\end{array}$} & \multirow{2}{*}{$\begin{array}{c}\text {-ve } \\
\% \\
\end{array}$} \\
\hline & & & & & & & \\
\hline $\mathrm{DI}(n=12)$ & $155.80 \pm 35.05$ & $90.2-200$ & $38.79 \pm 15.15$ & $20-60.2$ & $2.766 \pm 0.469$ & 58.33 & 41.67 \\
\hline NDI $(n=18)$ & $153 \pm 36.85$ & 87-190.7 & $33.11 \pm 12.39$ & $19.3-60$ & $1.066 \pm 0.0 .445$ & 44.44 & 55.56 \\
\hline Con. $(n=15)$ & $126.08 \pm 20.54$ & $88-155$ & $36.26 \pm 10.09$ & $19.5-50.7$ & $0.667 \pm 0.160$ & 0 & 100 \\
\hline$P$-value & \multicolumn{2}{|c|}{0.028} & \multicolumn{2}{|c|}{0.47} & \multicolumn{3}{|c|}{0} \\
\hline
\end{tabular}

DI: Diabetic, NDI: Non-diabetic, hsCRP: High sensitive C- reactive protein

Table 4: Mean concentration of serum complement components (C3, C4 mg/dl) and hsCRP (mg/L) in renal failure patients with HT, NHT patients, and control group (C)

\begin{tabular}{|c|c|c|c|c|c|c|c|}
\hline \multirow[t]{3}{*}{ Groups } & \multicolumn{2}{|c|}{$\mathrm{C} 3$} & \multicolumn{2}{|c|}{$\mathrm{C} 4$} & \multicolumn{3}{|c|}{ hsCRP } \\
\hline & Mean $(\mathrm{mg} / \mathrm{dl}) \pm \mathrm{SD}$ & Range (mg/dl) & Mean $(\mathrm{mg} / \mathrm{dl}) \pm \mathrm{SD}$ & Range (mg/dl) & Mean $(\mathrm{mg} / \mathrm{L}) \pm \mathrm{SD}$ & $+v e$ & -ve \\
\hline & & & & & & $\%$ & $\%$ \\
\hline HT $(n=25)$ & $154.45 \pm 35.95$ & $87-200$ & $36.78 \pm 14.35$ & $19-60$ & $1.84 \pm 0.99$ & 48 & 52 \\
\hline $\mathrm{NHT}(n=5)$ & $152.5 \pm 37.59$ & $100-180.5$ & $28.4 \pm 5.81$ & 23-37 & $1.26 \pm 0.705$ & 60 & 40 \\
\hline Con. $(n=15)$ & $144.77 \pm 33.85$ & $88-155$ & $36.26 \pm 10.09$ & $19.5-50.7$ & $0.667 \pm 0.160$ & 0 & 100 \\
\hline$P$-value & \multicolumn{2}{|c|}{0.028} & \multicolumn{2}{|c|}{0.388} & \multicolumn{3}{|c|}{0} \\
\hline
\end{tabular}

HT: Hypertension, NHT: Non-hypertension, hsCRP: High sensitive C- reactive protein 
Complement cascade activated in CKD progression and may participate in chronic inflammation; therefore, activation inhibiting would reduce inflammation this state result in the preservation of renal function and reduce fibrosis (Fearn and Sheerin, 2015).

Over the past few decades, some of the evidences have elucidated the complement activation associated with kidney disease progression. Abnormal regulation of complement cascade leads to a wide variety of renal disorders, including immunologic diseases and diseases that were thought to be nonimmunologic. Understanding the pathological mechanisms linked to complement activation and regulatory factors will help in the development of new therapeutic approaches (Wada and Nangaku, 2013). Increased excretion of proteins related to complement has been detected in patients with IgA nephropathy, systematic lupus erythematosus, and proteinuria patients (Ueda et al., 1995; Morita et al., 2000; Onda et al., 2011) as well as high blood pressure in pregnancy (Burwick et al., 2013).

In the present study collected, samples of kidney failure patients divided into six groups: Dialysis, non-dialysis, with diabetic, non-diabetic, with hypertension, and without hypertension. In dialysis, non-dialysis with diabetic, and non-diabetic groups $\mathrm{C} 3$ level recorded significant alteration compared to each group with control while C4 levels did not alter in each group when compared with control and remain within the normal value. This result may refer to the activation of the alternative pathways. C3 and C4 did not record significant differences in hypertension and nonhypertension comparing with control groups.

Abdul et al. (2006) study agrees with this study were they recorded a significant increasing $\mathrm{C} 3$ level and no significant change of C4 level in kidney failure patients. The study of Pan et al. (2017) disagreement with the present study, they showed an increase in serum C4 and decreased in serum C3 their study was done on patients with Immunoglobulin - A nephropathy while other study recorded elevation of C3 level in 30\% of IgA nephropathy (Zwirner et al., 1997). Furthermore, Zwirner et al. (1997) referred to several findings aid the concept of increasing the level of C3 reflects high grades of renal disease activity.

Poppelaars et al. (2018) reviewed that complement cascade is systematically activated during dialysis, and they mentioned C4 level remains normal during hemodialysis. Inoshita et al. (2010) concluded that the level of all three complement activities was significantly higher in the dialysis patients than the control group; these results agreed with this study regarding the result of patients under dialysis.

Flyvbjerg (2017) referred that C3 and membrane attack complex might be associated with kidney injury in hyperglycemia. Complement activation may be contributed to coronary disorder in the renal vesicular diseases associated with diabetes (Østergaard et al., 2005). Kelly et al. (2015) conclude that rapid renal injury in diabetic nephropathy was accompanied by local activation of the complement cascade. The defective of alternative pathway regulators is associated with kidney autoimmune diseases of the eye (Zipfel et al., 2006). Mustafa (2018) recorded C3 elevation in diabetic retinopathy patients.

The activation of the complement system has been involved in the pathophysiology of both hypertension and renal disease (Pechman et al., 2008). Plasma levels of $\mathrm{C} 3$ and $\mathrm{C} 4$ have been associated with hypertension and cardiovascular disorders (Engstrom et al., 2007; Nilsson et al., 2014). Transcriptomic analyses have indicated that the complement activation is upregulated in the kidney of the Dahl SS rat under a high-salt diet (Liu et al., 2014; Geurts et al., 2015). Regal et al. (2018) study indicated that complement activation is not critical for the development of the salt-sensitive phenotype, although alterations in the complement system may be occurring. Thus, the immune cells infiltration that amplifies the immune response and plays an important role in hypertension development and kidney damage is independent of the innate immune response.

The result of CRP showed a seropositivity range between 33.33 and $60 \%$ in all groups included in this study and hsCRP concentration recorded significant elevation in all patients groups compared with control. Several studies agreed with the present result, Razeghi et al. (2008) indicated that the CRP level was elevated in dialysis and pre-dialysis patients. Panichi et al. (2001) recorded increased serum CRP in $42 \%$. Stenvinkel et al. (1999) stated that 32\% of their patients had an elevated serum CRP level. In other study, the rate reached 35\% Ortega et al. (2002). hsCRP was found to be elevated in patients with CKDs compared to the control group (Kumar and Shobharani, 2015).

The present study concluded that the complement system is an important mediator of kidney injury and the role of anti-complement therapy in nephropathy will expand in the future. Kidney failure patients, even dialysis or not dialysis, diabetic or not diabetic, exhibited higher levels of C3 compared with control, which could explain the role of $\mathrm{C} 3$ in pathogenesis and reflects the severity of kidney injury.

\section{REFERENCES}

Abdul, H. H., I. Sahib and N. Hashim. 2006. Serum immunoglobulins and the complements $\mathrm{C} 3$ and $\mathrm{C} 4$ levels in the patients with chronic renal failure. Natl. J. Chem. 21: 125-132.

Angeletti, A., J. Reyes-Bahamonde, P. Cravedi and K. Campbell. 2017. Complement in non-antibody-mediated kidney diseases. 
Front. Med. 4: 1-10.

Bedford, M., C. Farmer, A. Levin, T. Ali and P. Stevens. 2012. Acute kidney injury and CKD: Chicken or egg? Am. J. Kidney Dis. 59: 485-491.

Burwick, R., R. Fichorova, H. Dawood, H. Yamamoto and B. Feinberg. 2013. Urinary excretion of c5b-9 in severe preeclampsia: Tipping the balance of complement activation in pregnancy. Hypertension. 62: 1040-1045.

Carroll, M. and D. Isenman. 2012. Regulation of humoral immunity by complement. Immunity. 37: 199-207.

Cravedi, P. and P. Heeger. 2014. Complement as a multifaceted modulator of kidney transplant injury. J. Clin. Invest. 124: 23482354.

Eknoyan, G., N. Lameire, R. Barsoum, K. Eckardt, A. Levin, N. Levin, F. Locatelli, A. MacLeod, R. Vanholder, R. Walker and H. Wang. 2004. The burden of kidney disease: Improving global outcomes. Kidney Int. 66(4): 1310-1314.

Engstrom, G., B. Hedblad, G. Berglund, L. Janzon and F. Lindgarde. 2007. Plasma levels of complement C3 is associated with development of hypertension: A longitudinal cohort study. J. Hum. Hypertens. 21: 276-282.

Fearn, A. and N. Sheerin. 2015. Complement activation in progressive renal disease. World J. Nephrol. 4(1): 31-40.

Flyvbjerg, A. 2017. The role of the complement system in diabetic nephropathy. Nat. Rev. Nephrol. 13(5): 311-318.

Geurts, A., D. Mattson, P. Liu, E. Cabacungan, M. Skelton, T. Kurth, C. Yang, B. Endres, J. Klotz, M. Liang and A. Cowley. 2015. Maternal diet during gestation and lactation modifies the severity of salt-induced hypertension and renal injury in Dahl saltsensitive rats. Hypertension. 65: 447-455.

Inoshita, H., I. Ohsawa, G. Kusaba, M. Ishii, K. Onda, S. Horikoshi, H. Ohi and Y. Tomino. 2010. Complement in patients receiving maintenance hemodialysis: Functional screening and quantitative analysis. BMC Nephrol. 11(34): 1-6.

Johnson, C., A. Levey, J. Coresh, A. Levin, J. Lau and G. Eknoyan. 2004. Clinical practice guidelines for chronic kidney disease in adults: Part 1. Definition, disease stages, evaluation, treatment and risk factors. Am. Fam. Physician. 70(5): 869-876.

Joshua, M. and M. Thurman. 2015. Complement in kidney disease: Core curriculum. Am. J. Kidney Dis. 65(1): 156-168.

Kelly, K., Y. Liu, J. Zhang and J. Dominguez. 2015. Renal C3 complement component: Feed forward to diabetic kidney disease. Am. J. Nephrol. 41(1): 48-56.

Khan, T. and K. Khan. 2015. Acute kidney injury and chronic kidney disease. Vet. Pathol. 52(3): 441-444.

Kościelska-Kasprzak, K., D. Bartoszek, M. Myszka, M. Żabińska and M. Klinger. 2014. The complement cascade and renal disease. Arch. Immunol. Ther. Exp. 62: 47-57.

Kumar, S. and B. Shobharani. 2015. Comparative study of hscrp in chronic kidney disease. IOSR J. Pharm. 5(7): 8-12.

Lameire, N., W. Van Biesen and R. Vanholder. 2005. Acute renal failure. Lancet. 365: 417-430.

Liu, Y., C. Liu, A. Yang, J. Cowley and M. Liang. 2014. Base-resolution maps of 5-methylcytosine and 5hydroxymethylcytosine in Dahl $S$ rats: Effect of salt and genomic sequence. Hypertension. 63: 827-838.

Morita, Y., H. Ikeguchi, J. Nakamura, N. Hotta, Y. Yuzawa and S. Matsuo. 2000. Complement activation products in the urine from proteinuric patients. J. Am. Soc. Nephrol. 11: 700-707.

Mustafa, N. 2018. Evaluation of complement components (C3 and C4) in diabetic retinopathy patients. Res. J. Pharm. Technol. 11(9): 3773-3776.

Nilsson, B., O. Hamad, H. Ahlstrom, J. Kullberg, L. Johansson, L. Lindhagen, A. Haenni, K. Ekdahl and L. Lind. 2014. C3 and $\mathrm{C} 4$ are strongly related to adipose tissue variables and cardiovascular risk factors. Eur. J. Clin. Invest. 44: 587-596.

Onda, K., I. Ohsawa, H. Ohi, M. Tamano, S. Mano, M. Wakabayashi, A. Toki, S. Horikoshi, T. Fujita and Y. Tomino. 2011. Excretion of complement proteins and its activation marker C5b-9 in IgA nephropathy in relation to renal function. BMC Nephrol. 12: 64 .

Ortega, O., I. Rodrigus and P. Gallar. 2002. Significance of high C-reactive protein levels in pre dialysis patients. Nephrol. Dial. Transplant. 17: 1105-1109.

Østergaard, J., T. Hansen, S. Thiel and A. Flyvbjerg. 2005. Complement activation and diabetic vascular complications. Clin. Chim. Acta. 361: 10-19.

Pan, M., J. Zhang, Z. Li, L. Jin, Y. Zheng, Z. Zhou, S. Zhen and G. Lu. 2017. Increased C4 and decreased C3 levels are associated with a poor prognosis in patients with immunoglobulin a nephropathy: A retrospective study. BMC Nephrol. 18(231): 1-7.

Panichi, V., M. Migliori, S. De Pietro, D. Taccola, A. Bianchi, M. Norpoth, M. Metelli, L. Giovannini, C. Tetta and R. Palla. 2001. C reactive protein in patients with chronic renal diseases. Ren. Fail. 23(3-4): 551-562.

Pechman, K., D. Basile, H. Lund and D. Mattson. 2008. Immune suppression blocks sodium-sensitive hypertension following recovery from ischemic acute renal failure. Am. J. Physiol. Regul. Integr. Comp. Physiol. 294: 1234-1239.

Poppelaars, F., B. Faria, M. da Costa, C. Franssen, W. van Son, S. Berger, M. Daha and M. Seelen. 2018. The complement system in dialysis: A forgotten story? Front. Immunol. 9: 71.

Razeghi, E., S. Parkhideh, F. Ahmadi and P. Khashayar. 2008. Serum CRP levels in pre-dialysis patients. Ren. Fail. 30: 193-198.

Regal, J., C. Laule, L. McCutcheon, K. Root, H. Lund, S. Hashmat and D. Mattson. 2018. The complement system in hypertension and renal damage in the Dahl SS rat. Physiol. Rep. 6(6): 1-6.

Stenvinkel, P., O. Heimbürger, F. Paultre, U. Diczfalusy, T. Wang, L. Berglund and T. Jogestrand. 1999. Strong association between malnutrition, inflammation, and atherosclerosis in chronic renal failure. Kidney Int. 55(5): 1899-1911.

Tang, Z. and N. Sheerin. 2009. Complement activation and progression of chronic kidney disease. Hong Kong J. Nephrol. 11(2): 41-46.

Ueda, Y., K. Nagasawa, H. Tsukamoto, T. Horiuchi, S. Yoshizawa, T. Tsuru, I. Furugo and Y. Niho. 1995. Urinary C4 excretion in systemic lupus erythematosus. Clin. Chim. Acta. 243: 11-23.

Wada, T. and M. Nangaku. 2013. Novel roles of complement in renal diseases and their therapeutic consequences. Kidney Int. 84(3): $441-450$

Zipfel, P., S. Heinen, M. Józsi and C. Skerka. 2006. Complement and diseases: Defective alternative pathway control results in kidney and eye diseases. Mol. Immunol. 43(1-2): 97-106.

Zwirner, J., M. Burg, M. Schulze, R. Brunkhorst, O. Götze, K. Koch and J. Floege. 1997. Activated complement C3: A potentially novel predictor of progressive IgA nephropathy. Kidney Int. 51(4): 1257-1264. 